\title{
m-Sübstitüeli Monoazo Boyarmaddeler: Sentez, Karakterizasyon ve Absorpsiyon Özellikleri
}

\author{
Tuğçe TÜRKMEN1(D), Barış SEZGİN1(D), Tahir TÍLKI*1®D \\ ${ }^{1}$ Süleyman Demirel Üniversitesi, Fen-Edebiyat Fakültesi, Kimya Bölümü, 32260, Isparta, Türkiye
}

(Alınış / Received: 19.08.2021, Kabul / Accepted: 29.11.2021, Online Yayınlanma / Published Online: 25.12.2021)

\section{Anahtar Kelimeler}

Azo boyarmadde,

Kenetleme reaksiyonu, Azo-hidrazon tautomerisi

\begin{abstract}
Özet: Azo boyarmaddelerin; boyama güçlerinin yüksek, ucuz başlangıç maddelerinden sentezlenebilmeleri, oldukça geniş bir renk skalasına sahip olmaları ve çeșitli özelliklerinin olması, bu maddeleri diğer organik bileșiklerden üstün kılmaktadır. Aromatik aminlerle sentezlenen azo boyarmaddeler, güçlü boyama kuvvetine sahip olmakta, çok parlak ve daha batokromik etkiye sahip, özellikle turuncu-sarı boyama aralığında fazla yüksek ıșık ve ağarma gibi kendine has özellikler göstermektedir. Çalışmamızda bu amaçla m-sübstitüeli karboksilik asit ve dioksan iskeletli monoazo boyarmaddelerin elde edilmesi ve daha batokromik renklerin sentezlenmesi hedeflenmiştir. Bunun için diazolanan bazı m-sübstitüeli aromatik aminlerin, 2,4-dihidroksi benzoik asit ve 2,2-dimetil 1,3-dioksan-4,6-dion ile azo kenetlenme reaksiyonu gerçekleștirilmiștir. Bileșiklerin yapıları, FT-IR, UVVis ve ${ }^{1} \mathrm{H}-\mathrm{NMR}$ gibi spektroskopik metotlar ile karakterize edilmiștir. Ayrıca sentezlenen bileşiklerin absorpsiyon spektrumları üzerinde çözücünün etkisi incelemek amacıyla 5 farklı çözücü içerisinde absorpsiyon özellikleri incelenmiştir. $\mathrm{Bu}$ çalışma ile literatüre yeni moleküller kazandırılarak, boyarmadde endüstrisine önemli katkılar sağlayacağı düşünülmektedir.
\end{abstract}

\section{m-Substituted Monoazo Dyes: Synthesis, Characterization and Absorption Properties}

\section{Keywords}

Azo dye,

Coupling reaction,

Azo-hydrazone tautomerism

\begin{abstract}
Azo dyes have high dyeing power, can be synthesized from cheap starting materials, have a wide color range and have various properties, which makes them superior to other organic compounds. Azo dyes synthesized with aromatic amines have strong dyeing strength, have a very bright and more bathochromic effect, show unique properties such as high light and bleaching, especially in the orange-yellow dyeing range. In our study, it was aimed to obtain monoazo dyes with $m$-substituted carboxylic acid and dioxane core and to synthesize more red shifting dyes. For this purpose, azo coupling reaction of some $m$-substituted aromatic amines diazotized with 2,4-dihydroxy benzoic acid and 2,2-dimethyl 1,3-dioxane-4,6-dione was performed. The structures of the compounds were characterized by spectroscopic methods such as FT-IR, UV-Vis and ${ }^{1} \mathrm{H}-\mathrm{NMR}$. In addition, absorption properties in different solvents were investigated in order to examine the effect of solvent on the absorption spectra of the synthesized compounds. It is thought that this study will contribute to the dyestuff industry by introducing new molecules to the literature.
\end{abstract}

\section{Giriş}

Azo boyarmaddeler, moleküler bağlamda azo grubu ($\mathrm{N}=\mathrm{N}-$ ) ile karakterize edilir ve boyarmaddeler arasında oldukça önemli bir yer tutar. Bu kromofordaki azot atomları, $\mathrm{sp}^{2}$ hibritizasyonu yaparak komşu karbon atomları ile bağ yapar $[1,2]$. Azo bileşikleri; boyalar, pigmentler ve gelişmiş malzemeler alanlarında çok önemlidir. Bununla birlikte, çok yönlülüğü nedeniyle birçok alanda uygulanırlar. En yaygın kullanımları tekstil endüstrisinde olmakla birlikte, aynı zamanda gıda, kozmetik, baskl, ilaç endüstrilerinde, renkli plastiklerde, sıvı kristal teknolojilerinde, polimerlerde, biyomedikal çalışmalarda ve organik sentezde ileri uygulamalar için kullanılmaktadırlar. Ayrıca azo bileşiklerinin DNA, RNA ve protein sentezi, azot fiksasyonu, kanser oluşumu gibi birçok mekanizmayı inhibe ettiği de bilinmektedir [3-5]. Kimyasal sensörler, LCD renk filtreleri, tekstil boyaları, redoks enzimleri için kromoforik substrat, optik polimerler, lazerler, doğrusal olmayan optik ve 
fotovoltaik üretim, ilaç, kozmetik, gıda ve organik sentez gibi daha birçok özel uygulamada başarıyla kullanılmaktadır [6-9]. Azo bileşikleri literatürde güçlü tıbbi değere sahip antimikrobiyal, antikanser, antiparaziter, analjezik, antioksidan gibi farmakolojik aktiviteler göstermektedir [10-16]. Monoazo boyar maddeler dispers boyar maddelerin büyük bir kısmını oluşturmaktadır. Dispers boyarmaddeler hidrofobik karakterli, suda çözünürlüğü çok az olan boyarmaddelerdir. Hem ekonomik hem de çevresel sonuçlar açısından azo boyarları antrakinon boyarlarının yerini almıştır. Antrakinon türevi yüzeyde eşit dağılan boyarmaddelerin boyama kuvvetlerinin az olması, üretiminde fazla aşama gerektirmeleri ve cıva kullanımı gibi ekonomik açıdan zararları vardır. Bu sebeplerden ötürü monoazo tipi boyarmaddelere artan ilgi gün geçtikçe devam etmektedir [17]. Aromatik aminlerle sentezlenen azo boyarmaddeler, güçlü boyama kuvvetine sahip olmakta, çok parlak ve daha batokromik etkiye sahip, özellikle turuncu-sarı boyama aralığında fazla yüksek ışık ve ağarma gibi kendine has özellikler göstermektedir [18, 19]. Azo boyaların rengi, azo bağları ve bunlarla ilişkili kromoforlar ve oksokromlar tarafından belirlenir. Boyaların rengi ve polaritesi, azo grubuna bağlı aromatik sübstitüentlerle ilişkilidir [2022]. Çalışmamızda bu amaçla m-sübstitüeli karboksilik asit ve dioksan iskeletli monoazo boyarmaddelerin elde edilmesi ve benzer bileşiklere göre daha batokromik renklerin sentezlenmesi hedeflenmiştir. Bunun için diazolanan bazı msübstitüeli aromatik aminlerin, 2,4-dihidroksi benzoik asit ve 2,2-dimetil 1,3-dioksan-4,6-dion ile azo kenetlenme reaksiyonu gerçekleştirilmiştir. Bileşiklerin yapıları, ${ }^{1} \mathrm{H}-\mathrm{NMR}$ (Proton Nükleer Manyetik Rezonans) ve FT-IR (Fourier Dönüşümlü Kızılötesi Spektroskopisi) ile karakterize edilmiştir. Ayrıca sentezlenen bileşiklerin absorpsiyon spektrumları üzerinde çözücünün etkisi incelemek amacıyla 5 farklı çözücü içerisinde absorpsiyon özellikleri UV-Vis (Ultraviyole Görünür Bölge Spektroskopisi) ile araştırılmıştır.

\section{Materyal ve Metot}

\subsection{Kullanılan kimyasallar ve cihazlar}

3-aminopiridin, 3-bromoanilin, m-toluidin, 2,4dihidroksibenzoik asit, 2,2-dimetil-1,3-dioksan-4,6dion, hidroklorik asit, sodyum nitrit, sodyum hidroksit, dimetil sülfoksit, dimetil formamid, HOAc, $\mathrm{CHCI}_{3}, \mathrm{MeOH}$ temin edilerek yeterli saflıkta kullanılmıştır. ${ }^{1} \mathrm{H}$-NMR analizleri için BrukerSpectrospinAvance DPX 400 Ultra-Shield cihazl, FT-IR analizleri için Shimadzu IR Prestige-21 Fourier cihazı kullanıldı. UV-Vis spektrumları, Schımadzu UV-1601 cihazı ile belirlendi. Sentezlenen bileșiklerin erime noktalarının belirlenebilmesi için Electrothermal 9100 Erime Noktası cihazı kullanıldı.

\subsection{Kimyasal sentez}

\subsubsection{2,4-dihidroksi-5-(piridin-3-ildiazenil) benzoik asit ( $3 a)$ bileşiğinin sentezi}

3-aminopiridin (0,01 mol, 0,94 gram) bileșiği üzerine 3,08 mL HCI eklendi ve bir miktar suda çözünerek tuzbuz karışımının üstüne konuldu. Üzerine 0,72 gram $\mathrm{NaNO}_{2}$ 'nin sulu çözeltisi sıcaklık sabit tutularak (0-($5^{\circ} \mathrm{C}$ )) yavaşça eklenip diazonyum tuzu oluşturuldu. Farklı bir tuz-buz ortamında kenetlenme bileșeni olarak kullanılan 2,4-dihidroksibenzoik asit (0,01 mol, 1,54 gram) üzerine 1 gram $\mathrm{NaOH}^{\prime}$ in sudaki çözeltisi ilave edildi. Elde edilen diazonyum tuzu, hazırlanan kenetlenme bileșeninin üzerine sicaklık $0^{\circ} \mathrm{C}$ üzerine çlkmadan yavaş yavaş eklenip 3 saat boyunca karıștırıldı. Oluşan karışım suyla çöktürüldü, süzüldü soğuk suyla yıkanıp vakum altında kurutuldu. Verim: \%80; E.N: $188-190^{\circ} \mathrm{C}$; Renk: turuncu; MA: $\mathrm{C}_{12} \mathrm{H}_{9} \mathrm{~N}_{3} \mathrm{O}_{4}=259,22 \mathrm{~g} / \mathrm{mol}{ }^{\mathbf{1}} \mathbf{H}-\mathrm{NMR}$ (400 MHz, DMSO$\left.\mathrm{d}_{6}\right): \delta(\mathrm{ppm})=8.77(\mathrm{~s}, \mathrm{OH}), 8.70(\mathrm{~s}, \mathrm{OH}), 8.40(\mathrm{~s}, \mathrm{Ar}-\mathrm{H})$, 8.28 (s, Ar-H), 7.90 (d, J $\approx 7.01 \mathrm{~Hz}, \operatorname{Ar}-\mathrm{H}), 7.83(\mathrm{~d}, \mathrm{~J} \approx$ $8.0 \mathrm{~Hz}, \mathrm{Ar}-\mathrm{H}), 7.46$ (s, Ar-H), 7.38 (s, Ar-H), 5.89 (s, COOH). FT-IR (KBr): $v_{\max }=(\mathrm{O}-\mathrm{H}): 3433 \mathrm{~cm}^{-1} ;(\mathrm{C}-\mathrm{H})$ : $3034 \mathrm{~cm}^{-1}$; (N=N): $1484 \mathrm{~cm}^{-1}$; (C=O): $1621 \mathrm{~cm}^{-1}$.

\subsubsection{2,2-dimetil-5-(2-(piridin-3-il) hidrazon)- 1,3-dioksan-4,6-dion (5a) bileşiğinin sentezi}

2.2.1.'deki prosedüre göre sentezlenmiștir. Verim: \%30; E.N: $172-174^{\circ} \mathrm{C}$; Renk: sarl; MA: $\mathrm{C}_{11} \mathrm{H}_{11} \mathrm{~N}_{3} \mathrm{O}_{4}$ $=249,22 \mathrm{~g} / \mathrm{mol}{ }^{1} \mathbf{H}-\mathbf{N M R}$ (400 MHz, DMSO-d 6$): \delta(\mathrm{ppm})$ $=13.27(\mathrm{~s}, \mathrm{~N}-\mathrm{H}), 8.91(\mathrm{~s}, \mathrm{Ar}-\mathrm{H}), 8.48(\mathrm{~d}, J \approx 4.1 \mathrm{~Hz}$, Ar$\mathrm{H}), 8.04(\mathrm{~d}, J \approx 8.1 \mathrm{~Hz}, \mathrm{Ar}-\mathrm{H}), 7.52(\mathrm{dd}, J \approx 7.9,4.6 \mathrm{~Hz}$, Ar-H), $1.77\left(\mathrm{~s}, 6 \mathrm{H}, 2 \mathrm{CH}_{3}\right)$. FT-IR $(\mathrm{KBr}): v_{\max }=(\mathrm{C}-\mathrm{H})$ : $3136 \mathrm{~cm}^{-1}$; (N-H): $1738 \mathrm{~cm}^{-1}$; (C=0): $1525 \mathrm{~cm}^{-1}$; (C=N): $1684 \mathrm{~cm}^{-1} ;\left(-\mathrm{CH}_{3}\right): 1401 \mathrm{~cm}^{-1}$.

\subsubsection{5-(2-(3-bromofenil) hidrazon)-2,2-dimetil- 1,3-dioksan-4,6-dion (7a) bileşiğinin sentezi}

2.2.1.'deki prosedüre göre sentezlenmiștir. Verim: \%55; E.N: $154-156^{\circ} \mathrm{C}$; Renk: turuncu; MA; $\mathrm{C}_{12} \mathrm{H}_{11} \mathrm{BrN}_{2} \mathrm{O}_{4}=327,13 \mathrm{~g} / \mathrm{mol} \quad \mathbf{1} \mathbf{H}-\mathbf{N M R} \quad(400 \mathrm{MHz}$, DMSO-d 6$): \delta(\mathrm{ppm})=13.15(\mathrm{~s}, \mathrm{~N}-\mathrm{H}), 7.85(\mathrm{t}, J \approx 1.8 \mathrm{~Hz}$, Ar-H), 7.67 - 7.63 (m, Ar-H), 7.42 (dd, $J \approx 12.7,7.3 \mathrm{~Hz}$, 2Ar-H), $1.72\left(\mathrm{~s}, 6 \mathrm{H}, 2 \mathrm{CH}_{3}\right)$. FT-IR $(\mathrm{KBr}): v_{\max }=(\mathrm{C}-\mathrm{H})$ : $3154 \mathrm{~cm}^{-1}$;(N-H): $1767 \mathrm{~cm}^{-1}$; (C-H): $3136 \mathrm{~cm}^{-1}$; (C=O): $1531 \mathrm{~cm}^{-1} ;(\mathrm{C}=\mathrm{N}): 1690 \mathrm{~cm}^{-1}$; $\left(-\mathrm{CH}_{3}\right): 1266 \mathrm{~cm}^{-1}$.

\subsubsection{2,2-dimetil-5-(2-(m-tolil) hidrazon)-1,3- dioksan-4,6-dion (9a) bileşiğinin sentezi}

2.2.1'deki prosedüre göre sentezlenmiștir. Verim: \%44; E.N: $113-115{ }^{\circ} \mathrm{C}$; Renk: turuncu; MA: $\mathrm{C}_{13} \mathrm{H}_{14} \mathrm{~N}_{2} \mathrm{O}_{4}=262,26 \mathrm{~g} / \mathrm{mol}{ }^{\mathbf{1}} \mathbf{H}-\mathbf{N M R}$ (400 MHz, DMSO$\left.\mathrm{d}_{6}\right): \delta(\mathrm{ppm})=13.26(\mathrm{~s}, \mathrm{~N}-\mathrm{H}), 7.46-7.39(\mathrm{~m}, 2 \mathrm{Ar}-\mathrm{H})$, 7.31 (dd, $J \approx 14.2,6.3 \mathrm{~Hz}, \mathrm{Ar}-\mathrm{H}), 7.08$ (d, J $\approx 7.4 \mathrm{~Hz}$, Ar$\mathrm{H}), 2.32\left(\mathrm{~s}, 3 \mathrm{H}, \mathrm{CH}_{3}\right), 1.71\left(\mathrm{~s}, 6 \mathrm{H}, 2 \mathrm{CH}_{3}\right)$. FT-IR (KBr): $\nu_{\max }=(\mathrm{C}-\mathrm{H}): 3142 \mathrm{~cm}^{-1}$; (N-H): $1725 \mathrm{~cm}^{-1}$; (C-H): 3136 
$\mathrm{cm}^{-1} ;(\mathrm{C}=\mathrm{O}): 1531 \mathrm{~cm}^{-1} ;(\mathrm{C}=\mathrm{N}): 1678 \mathrm{~cm}^{-1} ;\left(-\mathrm{CH}_{3}\right): 1384$ $\mathrm{cm}^{-1}$.

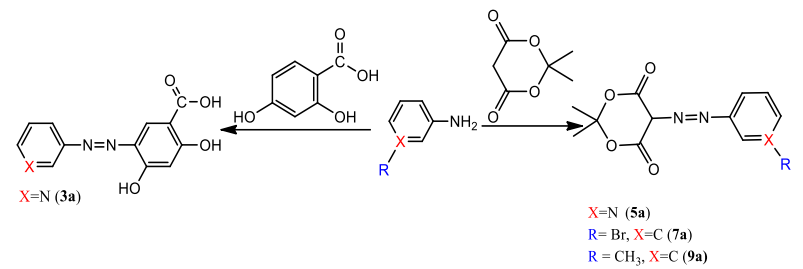

Şekil 1. Moleküllerin sentez șeması

Tautomeri, birbirine ve eski formuna dönebilen bileşiklerin denge halinde bulunmasıdır. Molekülün yapısında en az bir çifte bağın ve bir protonun göçüşü ile tautomerleşme meydana gelir [23]. Sentezlenen bileşiklerinin olası azo-hidrazon tautomer formları Şekil 2 - 4'de verilmiştir.<smiles>CC1(C)OC(=O)C(=NNc2cccnc2)C(=O)OC1(C)C</smiles>

Şekil 2. 5a bileşiğinin azo-hidarazon tautomerisi<smiles>CC1(C)OC(=O)C(=NNc2cccc(Br)c2)C(=O)OC1(C)C</smiles>

Şekil 3. 7a bileşiğinin azo-hidarazon tautomerisi<smiles>Cc1cccc(/N=N/C2C(=O)OC(C)(C)OC2=O)c1</smiles>

Şekil 4. 9a bileşiğinin azo-hidarazon tautomerisi

\section{Bulgular}

3a bileşiğinin DMSO- $\mathrm{d}_{6}$ içerisindeki ${ }^{1} \mathrm{H}-\mathrm{NMR}$ spektrumunda; $\delta=8.77 \mathrm{ppm}$ ve $\delta=8.70$ ppm'de hidroksil gruplarına ait pik, $\delta=8.4-\delta=7.38 \mathrm{ppm}$ arasında aromatik halkadaki protonları gösteren pikler ve $\delta=5.89$ ppm'de karboksilik asit protonuna ait bir pik görülmektedir. Şekil 1'de molekül yapısı verilen 3a bileşiğinin ${ }^{1} \mathrm{H}-\mathrm{NMR}$ spektrumu Şekil 5'de verilmiştir.

$5 \mathrm{a}$ bileşiğinin DMSO- $\mathrm{d}_{6}$ içerisindeki ${ }^{1} \mathrm{H}-\mathrm{NMR}$ spektrumunda; $\delta=13.27$ ppm'de azota bağlı protona (NH) ait pik, $\delta=8.91-\delta=7.52$ ppm arasında aromatik halkadaki protonları gösteren pikler ve $\delta=1.77 \mathrm{ppm}$ 'de iki metil grubundaki altı proton görülmektedir. Şekil 1'de molekül yapısı verilen $\mathbf{5 a}$ bileşiğinin ${ }^{1} \mathrm{H}-\mathrm{NMR}$ spektrumu Şekil 6'de verilmiştir.

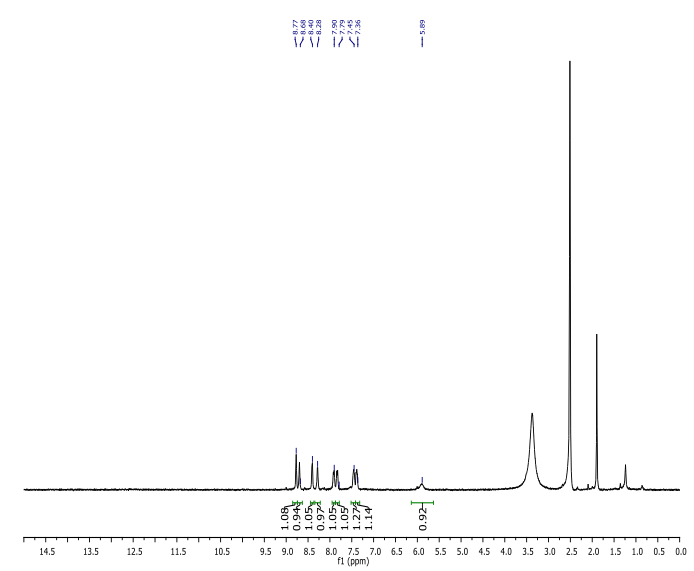

Şekil 5. Bileşik 3a'nın ${ }^{1} \mathrm{H}-\mathrm{NMR}$ spektrumu

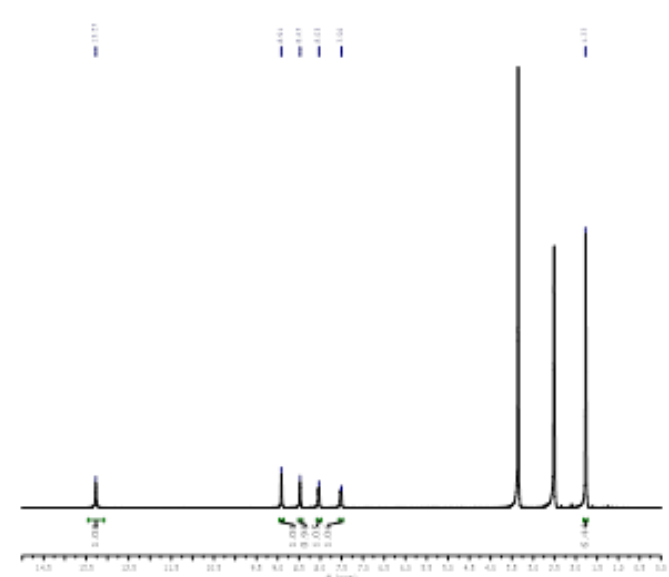

Şekil 6. Bileșik 5a'nın ${ }^{1} \mathrm{H}-\mathrm{NMR}$ spektrumu

7a bileşiğinin $\quad$ DMSO- $\mathrm{d}_{6}$ içerisindeki ${ }^{1} \mathrm{H}-\mathrm{NMR}$ spektrumunda; $\delta=13.15$ ppm'de azota bağlı protona $(\mathrm{NH})$ ait pik, $\delta=7.85$ ppm- $\delta=7.42$ ppm arasinda aromatik halkadaki protonları gösteren pikler ve $\delta=1.72$ ppm'de iki metil grubundaki altı proton görülmektedir. Şekil 1'de molekül yapısı verilen 7a bileşiğinin ${ }^{1} \mathrm{H}-\mathrm{NMR}$ spektrumu Şekil 7'de verilmiştir.

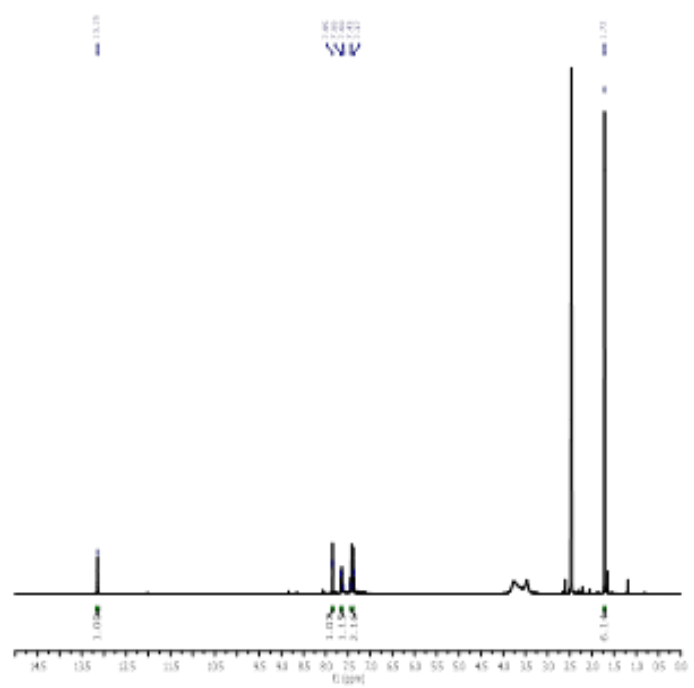

Şekil 7. Bileșik 7a'nın ${ }^{1} \mathrm{H}-\mathrm{NMR}$ spektrumu 
9a bileșiğin DMSO-d 6 içerisindeki ${ }^{1} \mathrm{H}-\mathrm{NMR}$ spektrumunda; $\delta=13.26$ ppm'de azota bağlı protona $(\mathrm{NH})$ ait pik, $\delta=7.46 \mathrm{ppm}-\delta=7.08 \mathrm{ppm}$ arasında aromatik halkadaki protonları gösteren pikler, $\delta=2.32$ ppm'de aromatik halkaya bağlı bir metil grubuna ait üç proton ve $\delta=1.71$ ppm'de alifatik halkaya bağlı iki metil grubuna ait altı proton görülmektedir. Şekil 1'de molekül yapısı verilen $\mathbf{9 a}$ bileşiğinin ${ }^{1} \mathrm{H}-\mathrm{NMR}$ spektrumu Şekil 8'de verilmiştir.

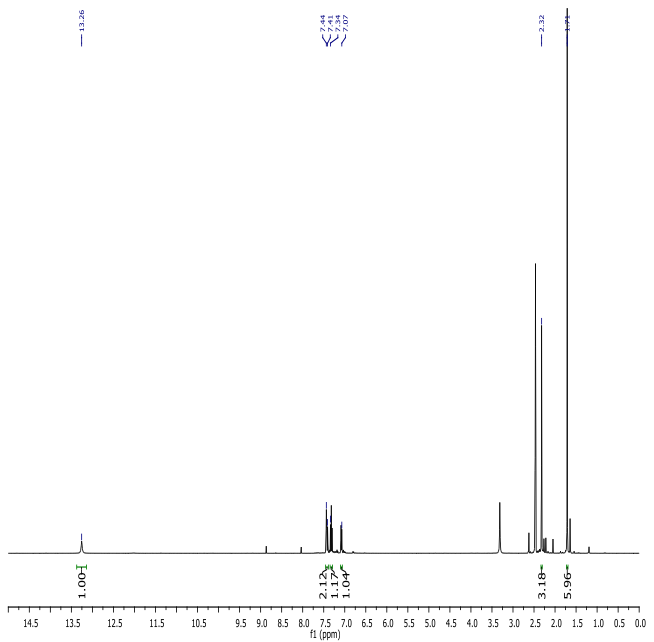

Şekil 8. Bileşik 9a'nın ${ }^{1} \mathrm{H}-\mathrm{NMR}$ spektrumu

3a bileşiğinin potasyum bromür içerisinde alınan FTIR spektrumunda; $3433 \mathrm{~cm}^{-1}$ 'de aromatik halkadaki O$\mathrm{H}, 3034 \mathrm{~cm}^{-1}$ 'de aromatik halkadaki C-H, $1621 \mathrm{~cm}^{-1}$ 'de aromatik halkadaki $\mathrm{HO}-\mathrm{C}=0,1484 \mathrm{~cm}^{-1}$ 'deki bant ise $\mathrm{N}=\mathrm{N}$ - gerilme titreşiminden ileri gelmektedir. Şekil 1'de molekül yapısı verilen $\mathbf{3 a}$ bileşiğinin FT-IR spektrumu Şekil 9'da verilmiştir.

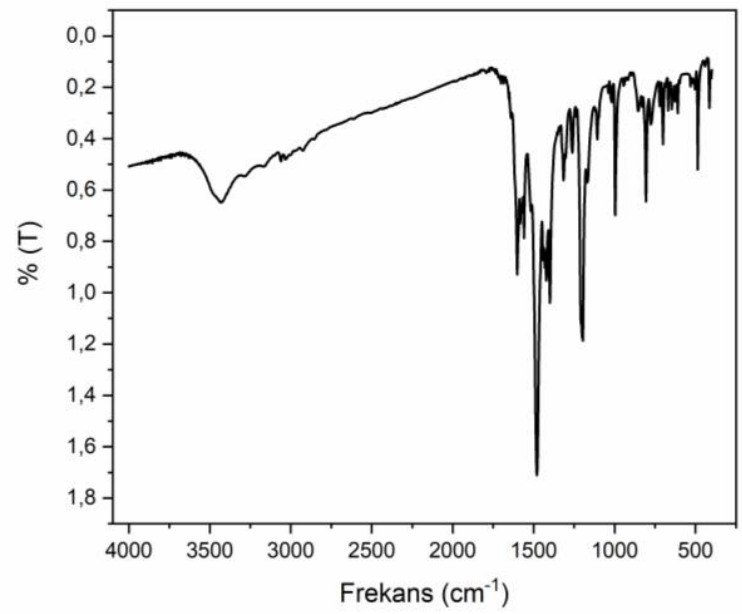

Şekil 9. Bileşik 3a'nın FT-IR spektrumu

5a bileşiğinin potasyum bromür içerisinde alınan FTIR spektrumunda; $3136 \mathrm{~cm}^{-1}$ 'de aromatik halkadaki C$\mathrm{H}, 1738 \mathrm{~cm}^{-1}$ de aromatik halkaya bağlı N-H, $1684 \mathrm{~cm}^{-}$ ${ }^{1}$ 'de $-\mathrm{C}=\mathrm{N}$ - ve $1525 \mathrm{~cm}^{-1}$ 'de $-\mathrm{C}=\mathrm{O}$ - gerilme titreşiminden, $1401 \mathrm{~cm}^{-1}$ 'deki bant ise $-\mathrm{CH}_{3}$ eğilme titreşiminden ileri gelmektedir. Şekil 1'de molekül yapısı verilen $\mathbf{5 a}$ bileşiğinin FT-IR spektrumu Şekil 10'de verilmiştir.

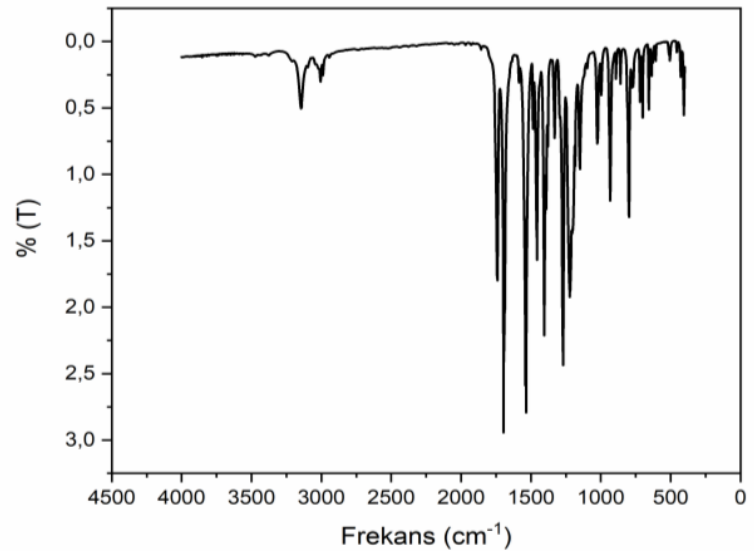

Şekil 10. Bileșik 5a'nın FT-IR spektrumu

7a bileșiğinin potasyum bromür içerisinde alınan FTIR spektrumunda; $3154 \mathrm{~cm}^{-1}$ 'de aromatik halkadaki C$\mathrm{H}, 1767 \mathrm{~cm}^{-1}$ 'de aromatik halkaya bağlı N-H, $1690 \mathrm{~cm}^{-}$ ${ }^{1}$ 'de $-\mathrm{C}=\mathrm{N}$ - ve $1531 \mathrm{~cm}^{-1}$ 'de $-\mathrm{C}=\mathrm{O}$ - gerilme titreşiminden, $1266 \mathrm{~cm}^{-1}$ 'deki bant ise $-\mathrm{CH}_{3}$ eğilme titreşiminden ileri gelmektedir. Şekil 1'de molekül yapısı verilen $7 \mathbf{a}$ bileşiğinin FT-IR spektrumu Şekil 11'de verilmiştir.

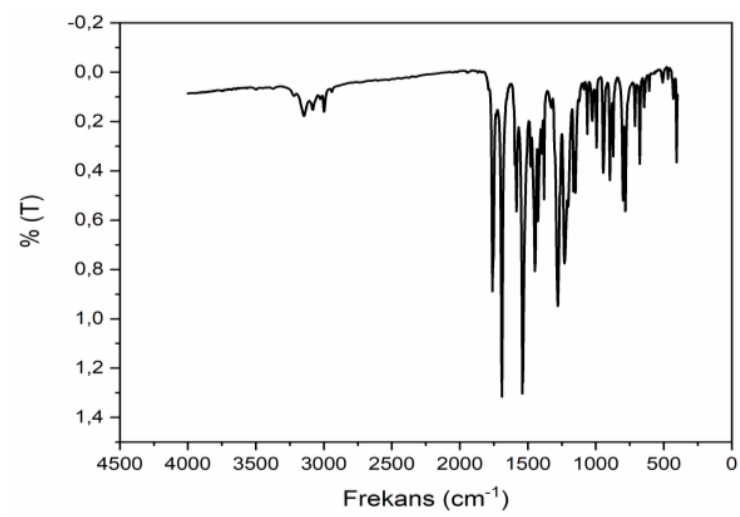

Şekil 11. Bileşik 7a'nın FT-IR spektrumu

9a bileșiğinin potasyum bromür içerisinde alınan FTIR spektrumunda; $3142 \mathrm{~cm}^{-1}$ 'de aromatik halkadaki C$\mathrm{H}, 1725 \mathrm{~cm}^{-1}$ 'de aromatik halkaya bağlı $\mathrm{N}-\mathrm{H}, 1678 \mathrm{~cm}^{-}$ ${ }^{1}$ 'de $-\mathrm{C}=\mathrm{N}$ - ve $1531 \mathrm{~cm}^{-1}$ 'de $-\mathrm{C}=\mathrm{O}$ - gerilme titreşiminden, $1384 \mathrm{~cm}^{-1}$ 'deki bant ise $-\mathrm{CH}_{3}$ eğilme titreșiminden ileri gelmektedir. Şekil 1'de molekül yapısı verilen 9a bileşiğinin FT-IR spektrumu Şekil 12'de verilmiştir.

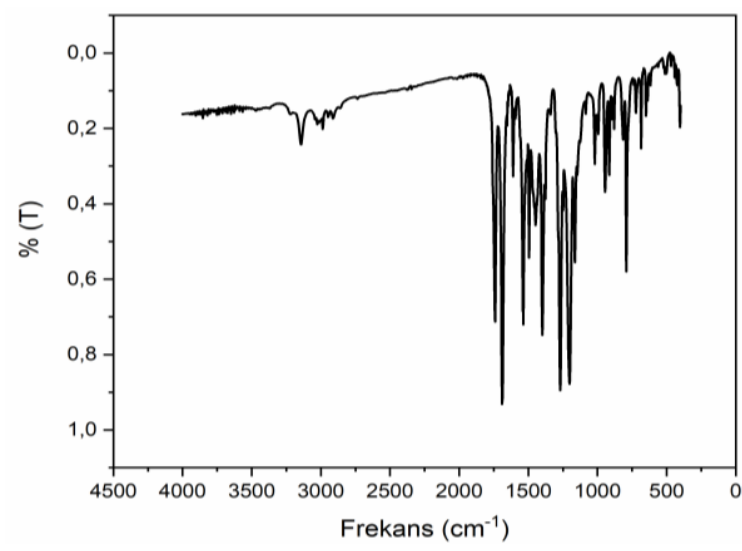

Şekil 12. Bileşik 9a'nın FT-IR spektrumu 
Sentezlenen bileşiklere ait FT-IR spektrum verileri Tablo 1'de verilmiştir.

Tablo 1. Sentezlenen bileşiklerin bazı seçilmiş FT-IR spektrum değerleri

\begin{tabular}{cccccc}
\hline & $\mathbf{V}_{\text {Ar-H }}$ & $\mathbf{V}_{\text {Alif-H }}$ & $\mathbf{V}_{\mathbf{N}=\mathbf{N}}$ & $\mathbf{V}_{\mathbf{N}-\mathbf{H}}$ & $\mathbf{V}_{\mathbf{C}=\mathbf{O}}$ \\
\hline 3a & 3034 & - & 1484 & - & 1600 \\
$\mathbf{5 a}$ & 3136 & 1401 & - & 1536 & 1690 \\
$\mathbf{7 a}$ & 3154 & 1266 & - & 1543 & 1684 \\
$\mathbf{9 a}$ & 3142 & 1384 & - & 1531 & 1631 \\
\hline
\end{tabular}

Bileşik 3a'nın 1x10-6 M konsantrasyonda hazırlanan $\mathrm{HOAc}, \mathrm{MeOH}$, DMSO, $\mathrm{CHCI}_{3}$ ve DMF içerisindeki spektrumlarında bir tane maksimum gözlenmektedir. $\mathrm{HOAc}, \mathrm{MeOH}, \mathrm{DMSO}, \mathrm{CHCI}_{3}$ ve DMF'nin $\lambda_{\text {mak }}$ verileri incelendiğinde soğurma ve çözücü maksimumlarının değişmediği gözlenirken, $\mathrm{MeOH}$ ve $\mathrm{HOAc}$ ise $\mathrm{CHCI}_{3}$ 'a göre daha hipsokromik kayma, DMF ve DMSO'da ise $\mathrm{CHCI}_{3}$ 'a göre daha batokromik kayma göstermektedir. Şekil 1'de molekül yapısı verilen 3a bileșiğinin UV-Vis spektrumu Şekil 13'da verilmiştir.

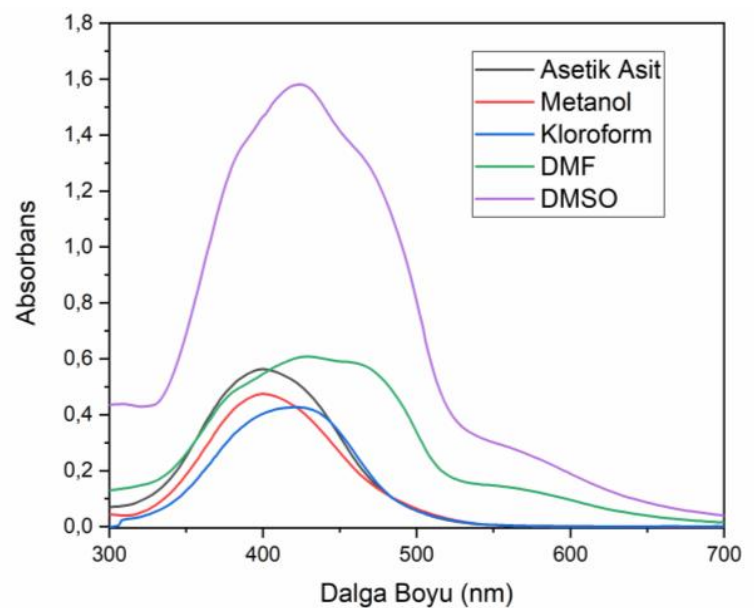

Şekil 13. Bileşik 3a 'nın farklı çözücülerde absorpsiyon spektrumları

Bileşik 5a'nın 1×10-6 M konsantrasyonda hazırlanan $\mathrm{MeOH}$ ve HOAc içerisindeki spektrumunda çift maksimum gözlemlenirken DMSO, $\mathrm{CHCI}_{3}$ ve DMF içerisindeki spektrumlarında bir tane maksimum gözlenmektedir. $\mathrm{HOAc}$, DMSO, $\mathrm{MeOH}, \mathrm{CHCl}_{3}$ ve DMF'nin birinci $\lambda_{\text {mak }}$ verileri incelendiğinde soğurma ve çözücü maksimumlarının değişmediği gözlenirken, $\mathrm{MeOH}, \mathrm{DMF}, \mathrm{DMSO}$ ve $\mathrm{HOAc}$ ise $\mathrm{CHCI}_{3}$ 'a göre hipsokromik kayma göstermektedir. İkinci $\lambda_{\text {mak }}$ verileri incelendiğinde $\mathrm{MeOH}$ ve HOAc içindeki soğurma ve çözücü maksimumları $\mathrm{CHCI}_{3}$ 'a göre batokromik kayma göstermektedir. Şekil 1'de molekül yapısı verilen $\mathbf{5 a}$ bileşiğinin UV-Vis spektrumu Şekil 14'de verilmiştir.

Bileşik 7a'nın 1x10-6 M konsantrasyonda hazırlanan HOAc içerisindeki spektrumunda çift maksimum gözlemlenirken DMSO, $\mathrm{CHCI}_{3}$, DMF ve $\mathrm{MeOH}$ içerisindeki spektrumlarında bir tane maksimum gözlenmektedir. $\mathrm{CHCI}_{3}, \mathrm{DMSO}, \mathrm{MeOH}, \mathrm{HOAc}$ ve DMF'nin ilk $\lambda_{\text {mak }}$ verileri incelendiğinde soğurma ve çözücü maksimumlarının değişmediği gözlenirken, DMSO, HOAc, $\mathrm{MeOH}$ ve DMF ise $\mathrm{CHCI}_{3}$ 'a göre hipsokromik kayma göstermektedir. İkinci $\lambda_{\text {mak }}$ verileri incelendiğinde HOAc içindeki soğurma ve çözücü maksimumları $\mathrm{CHCI}_{3}$ 'a göre batokromik kayma göstermektedir. Şekil 1'de molekül yapısı verilen 7a bileşiğinin UV-Vis spektrumu Şekil 15'de verilmiştir.

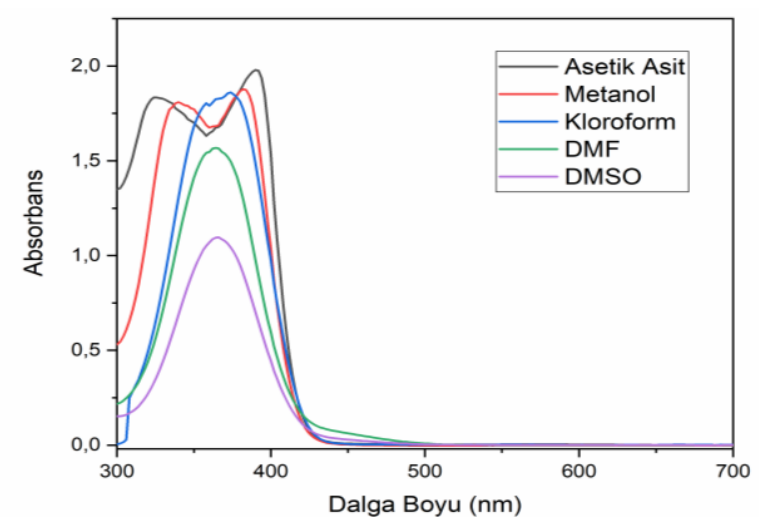

Şekil 14. Bileşik 5a 'nın farklı çözücülerde absorpsiyon spektrumları

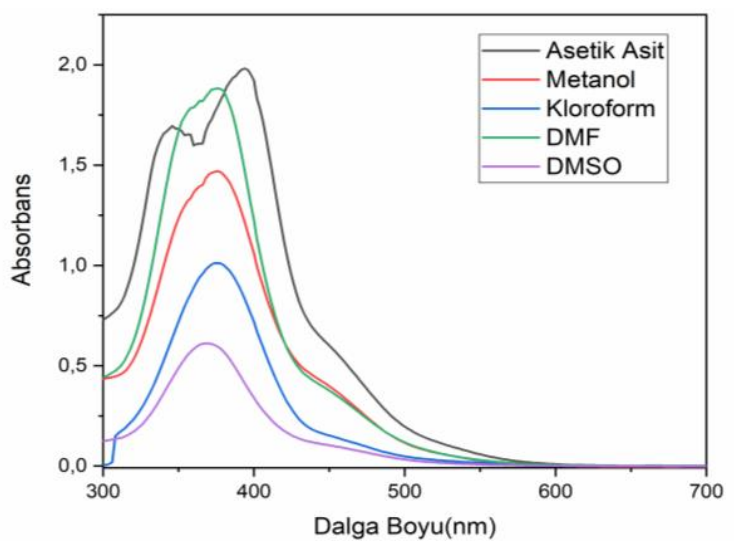

Şekil 15. Bileșik 7a'nın farklı çözücülerde absorpsiyon spektrumları

Bileşik 9a'nın 1x10-6 M konsantrasyonda hazırlanan $\mathrm{HOAc}, \mathrm{MeOH}, \mathrm{DMSO}, \mathrm{CHCI}_{3}$ ve DMF içerisindeki spektrumunda bir tane maksimum gözlenmektedir. DMSO, $\mathrm{HOAc}, \mathrm{MeOH}, \mathrm{CHCI}_{3}$ ve DMF'nin ilk $\lambda_{\text {mak }}$ verileri incelendiğinde soğurma ve çözücü maksimumlarının pek fazla değişmediği gözlemlenirken, DMSO, DMF, $\mathrm{HOAc}$ ve $\mathrm{MeOH}, \mathrm{CHCI}_{3}$ 'a göre daha hipsokromik kayma göstermektedir. Şekil 1'de molekül yapısı verilen 9a bileşiğinin UV-Vis spektrumu Şekil 16'da verilmiştir.

Sentezlenen bileşiklere ait UV-Vis spektrum verileri Tablo 2'de verilmiştir.

Tablo 2. Bileşiklerin farklı çözücülerdeki dalga boylarının değișimi (nm)

\begin{tabular}{cccccc}
\hline & HOAc & MeOH & CHCI $_{\mathbf{3}}$ & DMF & DMSO \\
\hline 3a & 397 & 399 & 420 & 438 & 423 \\
$\mathbf{5 a}$ & $324-390$ & $339-381$ & 366 & 362 & 365 \\
$\mathbf{7 a}$ & $344-393$ & 373 & 376 & 374 & 370 \\
$\mathbf{9 a}$ & 381 & 382 & 387 & 376 & 378 \\
\hline
\end{tabular}




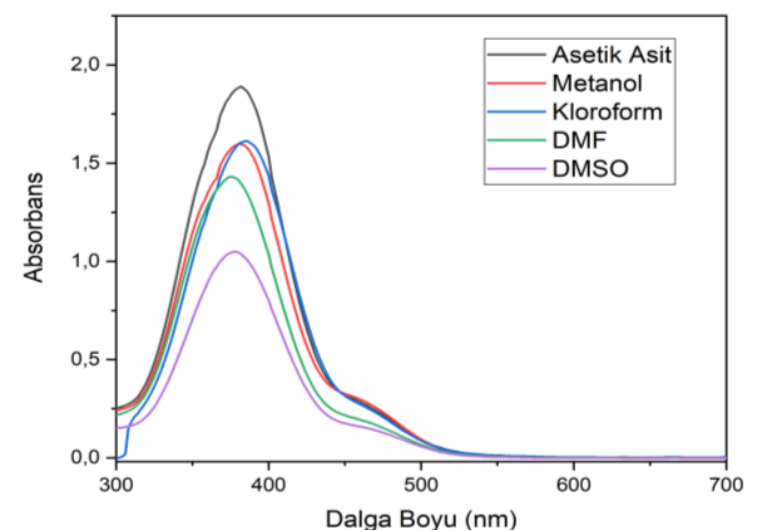

Şekil 16. Bileşik 9a 'nın farklı çözücülerde absorpsiyon spekturumları

\section{Tartışma ve Sonuç}

3a ve $\mathbf{5 a}$ bileşiklerinin ${ }^{1} \mathrm{H}-\mathrm{NMR}$ spektrumları incelendiğinde $\mathbf{3 a}$ bileșiğinin $\mathbf{5 a}$ bileșiğine göre daha yukarı alanda rezonans olduğu gözlemlendi. Dioksan iskeletine sahip bileşiklerin ${ }^{1} \mathrm{H}-\mathrm{NMR}$ spektrumları incelendiğinde, bu bileşiklerin hidrazon formunda olduğu belirlendi. Aynı zamanda FT-IR ile gerçekleştirilen karakterizasyonda $\mathbf{3 a}$ bileşiğine ait $\mathrm{N}=\mathrm{N}$ çifte bağ titreşimi gözlemlenirken $\mathbf{5 a}, \mathbf{7 a}$ ve $\mathbf{9 a}$ bileşiklerine ait $\mathrm{N}-\mathrm{H}$ gerilme titreşimleri gözlemlendi. FT-IR spektrumları, bu bileşiklerin hidrazon formunda olduğunu doğrulamaktadır.

Farklı çözücülerde hazırlanan bileșiklerin UV-Vis spektrumları $\mathrm{CHCI}_{3}$ 'a göre incelendiğinde polariteden dolayı 3a bileşiğinde kırmızıya kayma (batokromik etki), 9a bileşiğinde maviye kayma (hipsokromik etki) gözlemlenmiştir. 5a ve 7a bileşiklerinde ise birinci maksimumda maviye kayma (hipsokromik etki) gözlemlenirken ikinci maksimumlarda kırmızıya kayma (batokromik etki), gözlemlenmiștir. $\mathrm{Bu}$ bileşiklerde gözlemlediğimiz çift maksimumlar iki tautomerik formun bir arada bulunduğunu göstermektedir.

Sentezlenen bileşiklerin boyama gücü daha iyi olan ve uzun dalga boyunda absorpsiyon yapan hidrazon formu bu çalışmada kararlı form olarak öne çıkmıştır. Bu çalışma ile, literatüre ve boyarmadde endüstrisine yeni boyarmaddeler kazandırılmış olup sentezlenen bu boyarmaddelerin yeni çalıșmalara zemin hazırlayarak biyolojik aktivite çalışmalarında kullanım alanı bulacağı düşünülmektedir.

\section{Teşekkür}

Bu çalışmanın gerçekleşmesi için gerekli maddi destek için Süleyman Demirel Üniversitesi Bilimsel Araştırma Projeleri Koordinasyon Birimine (FYL-2019-6937) teșekkür ederim.

\section{Etik Beyanı/Declaration of Ethical Code}

Bu çalışmada, "Yükseköğretim Kurumları Bilimsel Araștırma ve Yayın Etiği Yönergesi" kapsamında uyulması gerekli tüm kurallara uyulduğunu, bahsi geçen yönergenin "Bilimsel Araştırma ve Yayın Etiğine Aykırı Eylemler" başlığı altında belirtilen eylemlerden hiçbirinin gerçekleştirilmediğini taahhüt ederiz.

\section{Kaynakça}

[1] Bakan, E. 2015. Pirazol türevi yeni dispers disazo boyarmaddelerin sentezi ve spektroskopik ve haslık özelliklerinin incelenmesi. Pamukkale Üniversitesi, Fen Bilimleri Enstitüsü, Doktora Tezi, 229s, Denizli.

[2] Ertan, N. 2000. Synthesis of some hetarylazopyrazolone dyes and solvent effects on their absorption spectra. Dyes and Pigments, 44(1), 41-48.

[3] Lin, T.H., Tsai, Y.T., Zheng, W. 2009. Photoalignment effenct in a liquid-crystal film doped with nanoparticles and azo-dye. Applied Physics Letters, 94, 201114.

[4] Șener, İ., Șener, N., Gür, M. 2018. Synthesis, structural analysis, and absorption properties of disperse benzothiazol-derivative mono-azo dyes. Journal of Molecular Structure, 12-17.

[5] Badea, M., Olar, R., Cristurean, E., Marinescu, D., Emandi A., Budrugeac, P. 2004. Thermal stability study of some azo-derivatives and their complexes: part 2. New azo-derivative pigments and their $\mathrm{Cu}$ (II) complexes. Journal of Thermal Analysis and Calorimetry, 77(3), 815-824.

[6] Derkowska-Zielinska, B., Gondek, E., PokladkoKowar, M., Kaczmarek-Kedziera, A., Kysil, A., Lakshminarayana, G., Krupka O. 2020. Photovoltaic cells with various azo dyes as components of the active layer. Solar Energy, 203, 19-24.

[7] Derkowska-Zielinska, B., Matczyszyn, K., Dudek, M., Samoc, M., Czaplicki, R., Kaczmarek-Kedziera, A., Smokal V., Biitseva, A., Krupka O. 2019. Alloptical poling and two-photon absorption in heterocyclic azo dyes with different side groups. Journal of Physical Chemistry, 123, 725734.

[8] Derkowska-Zielinska, B., Szmigiel, D., Kysil, A., Krupka, O., Kozanecka-Szmigiel A. 2020. Photoresponsive behavior of heterocyclic azo polymers with various functional groups. Journal of Physical Chemistry, 124, 939-944.

[9] Unnisa, A., Abouzied, S.A., Baratam, A., Lakshmi, K.N.V.C., Hussain, T., Kunduru, R.D., Banu, H., Fatima, S.B., Hussian, A., Selvarajan, K.K. 2020. Design, synthesis, characterization, computational study and in-vitro antioxidant and anti-inflammatory activities of few novel 6-aryl substituted pyrimidine azo dyes. Arabian Journal of Chemistry, 13(12), 8638-8649.

[10] Altaf, A.A., Shahzad, A., Gul, Z., Rasool, N., Badshah, A., Lal, B. 2015. A review on the 
medicinal importance of pyridine derivatives. Journal of Drug Design and Medicinal Chemistry, 1(1), 1-11.

[11] Chaubey, A., Pandeya, S.N. 2011. Pyridine a versatile nucleuse in pharmaceutical field. Asian Journal of Pharmaceutical and Clinical Research, $4(4), 5-8$.

[12] Fadda, A.A., Berghot, M.A., Amer, F.A., Badawy, D.S., Bayoumy, N.M. 2012. Full paper synthesis and antioxidant and antitumor activity of novel pyridine. Archiv Der Pharmazie, 345(5), 378385.

[13] Hamada, Y. 2018. Role of pyridines in medicinal chemistry and design of BACE1 inhibitors possessing a pyridine scaffold. In Pyridine, Chapter 2, 9-26.

[14] Li, Q., Zhang, C., Tan, W., Gu, G., Guo, Z. 2017. Novel amino-pyridine functionalized chitosan quaternary ammonium derivatives: Design. Molecules, 22(1), 156.

[15] Mallesha, L., Karthik, C. S., Kumar, C., Mallu, P. 2016. Synthesis, antioxidant and antihemolytic activities of (4-nitrobenzylidene)-pyridin-3ylmethyl amine. Chemical Science Review and Letters, 5(18), 183-190.

[16] Sezgin, B., Tilki, T., Dede, B., Atay, Karabacak, Ç. 2020. Comparative in vitro and DFT antioxidant studies of phenolic group substituted pyridinebased azo derivatives. Journal of Biomoleculer
Structure and Dynamics, 1-12.

[17] Zollinger, H. 1990. Color chemistry: Synthese, properties and applications of organic dyes and pigments. Colour Chemistry. $2^{\text {nd }} \mathrm{VCH}$, Weinheim, New York.

[18] Karcl, F. 2005. Synthesis of disazo dyes derived from heterocyclic components. Coloration Technology, 121, 275-282.

[19] Karabacak, Ç. 2011. Pirazol halkası içeren bazı yeni disazo boyarmaddelerinin sentezi ve spektroskopik özelliklerinin incelenmesi. Süleyman Demirel Üniversitesi, Fen Bilimleri Enstitüsü, Doktora Tezi, 163s. Isparta.

[20] Başer, İ., İnancı, Y. 1990. Boyarmadde Kimyası, İstanbul.

[21] Basan, S., İmren, D., Yüce, S. 2001. Kimyasal Teknolojiler ve Analizler, Cumhuriyet Üniversitesi Yayınları, Sivas.

[22] Bayram, S. (2014). Reaktif azo boyarmaddelerin $\mathrm{TiO}_{2}$ yüzeyinde adsorpsiyon dekolorizasyon reaksiyonlarının kinetik incelemesi. Yıldız Teknik Üniversitesi, Fen Bilimleri Enstitüsü, Yüksek Lisans Tezi, 124s, İstanbul.

[23] Karabulut. S., 2011. Düz zincirli imitlerin sentezi, imitlerin ve 1,3-dikarbonil bileşiklerinin tautomer oranlarının deneysel ve hesapsal olarak incelenmesi. Balıkesir Üniversitesi, Fen Bilimleri Enstitüsü, Doktora Tezi, 122s, Balıkesir. 